\title{
CREATING THE ONTOLOGY OF THE SUBJECT AREA OF THE STORING OF VEGETABLES AND FRUITS BY THE TECHNOLOGY «ULO»
}

\author{
Yevhen Proskurka,
} Assistant of the Department Automation and Computer Technology of the Management Systems,

Ivan Chelyshev, Student of the Faculty Automation and Computer System, National University of Food Technologies, 01601, Volodymyrska str. 68, Ukraine, Kyiv

\section{ABSTRACT}

Creating the ontology of the subject area of the storing of vegetables and fruits by the technology «ULO» for future using in the knowledge base of the expert system is reviewed in the article. The expert system will be used for manage of the automation system of the storehouse for the storing of vegetables and fruits by the technology «ULO».

Keywords: ontology, technology «ULO», expert system.

The technology «ULO» (Ultra Low Oxygen) for the storing of vegetables and fruits is getting popularity at that moment. The essence of the technology «ULO» is managing of the content $\mathrm{CO}_{2}$ and $\mathrm{O}_{2}$ in air of the storehouse.

The necessary equipment for implementing the technology «ULO» in the storehouse for vegetables and fruits is shown in the fig. 1 [1].

The requirements of the content $\mathrm{CO}_{2}$ and $\mathrm{O}_{2}$ in air of the storehouse, as well as temperature, humidity and term of the storing in the storehouse is existed for each type of vegetables and fruits. The requirements of the storing of vegetables and fruits by the technology «ULO» is shown in the fig. $2[2,3]$.

It is proposed to create an ontology of the subject area of the storing of vegetables and fruits using the technology «ULO», which would describe the requirements of the storing of vegetables and fruits according this technology. 


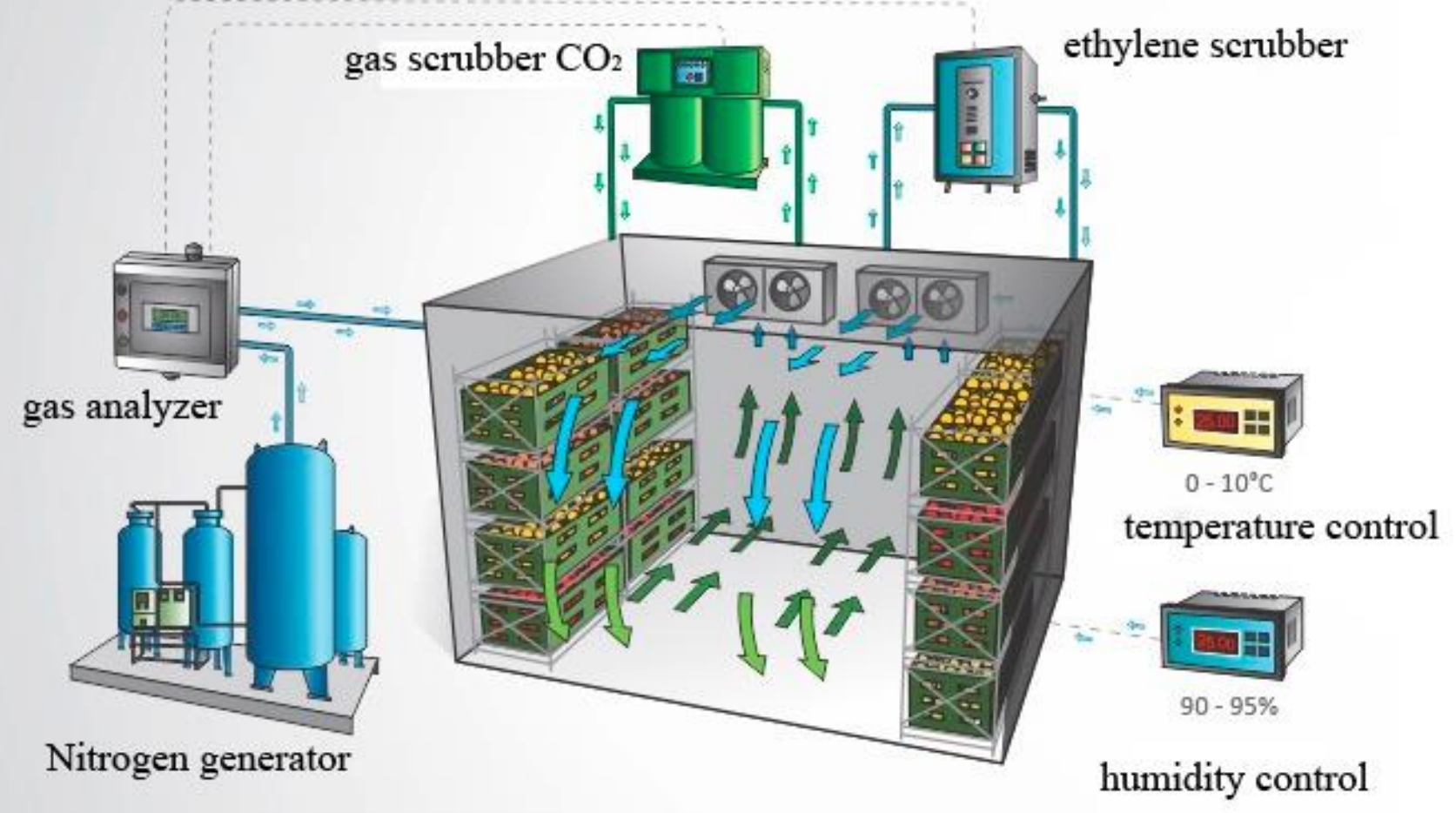

Figure 1. Equipment for implementing the technology «ULO».

Protégé software was used for creating the ontology of the subject area of the storing of vegetables and fruits using the technology «ULO» [4]. The created of the ontology of the subject area of the storing of vegetables and fruits using the technology «ULO» is shown as a graph model in the fig. 3.

The main class Products includes classes Fruits and Vegetables. The classes Fruits and Vegetables include the classes of the different types of vegetables and fruits, which is shown in the graph model in the fig. 3.

The main class Products includes next slots: Days, Name, CO2, Temp, Hum, and $\mathrm{O} 2$, which describe the requirements of the storing of vegetables and fruits by the technology «ULO». The classes of the types of vegetables and fruits are inherited these slots from classes Fruits and Vegetables, which are inherited these slots from the main class Products.

The organization of slots in the each class of the ontology and filling each slot with data, which is meets the requirements of the storing of vegetables and fruits by the technology «ULO» is shown in the fig. 4, used the example of the class Orange, which describes the requirements of the storing of oranges. 


\begin{tabular}{|c|c|c|c|c|c|}
\hline Name & $\begin{array}{c}\text { Temperature, } \\
{ }^{\circ} \mathrm{C}\end{array}$ & Humidity, \% & $\begin{array}{l}\text { Term of } \\
\text { storing }\end{array}$ & $\begin{array}{c}\text { Concentration } \\
\mathrm{O}_{2}, \%\end{array}$ & $\begin{array}{c}\text { Concentration } \\
\mathrm{CO}_{2}, \%\end{array}$ \\
\hline Apricot & $-0,5 \ldots+0,5$ & 90 & $4-6$ weeks & $2-3$ & 5 \\
\hline Avocado & $+5 \ldots+7$ & 90 & $2-4$ weeks & 2 & $3-5$ \\
\hline Orange & $0 \ldots+9$ & $85-90$ & $8-12$ weeks & $5-10$ & 2,5 \\
\hline Eggplant & $+10 \ldots+12$ & $90-95$ & 20 days & $3-5$ & 10 \\
\hline Green bananas & $+13 \ldots+14$ & $90-95$ & $4-6$ weeks & $2-5$ & $2-5$ \\
\hline Grape & $-0,5 \ldots+5$ & $90-95$ & 5-7 months & $3-5$ & $1-3$ \\
\hline Cherry & 0 & $90-95$ & 20 days & 3 & 5 \\
\hline Pear & $-1 \ldots+1$ & $90-95$ & до 10 months & $1-3$ & $0-4$ \\
\hline White cabbage & $-1 \ldots+1$ & $95-100$ & до 9 months & $2-3$ & $3-5$ \\
\hline Chinese cabbage & 0 & $95-100$ & $2-3$ months & $1-2$ & $0-2$ \\
\hline Red cabbage & 0 & $95-100$ & 4-7 months & $3-5$ & $5-7$ \\
\hline Cabbage Savoy & 0 & $95-100$ & 4-6 months & $3-5$ & $5-7$ \\
\hline Kiwi & $0 \ldots+5$ & $90-95$ & 6 months & $1-2$ & $3-5$ \\
\hline Lemon & $+7 \ldots+12$ & 85 & 6 months & $5-10$ & $0-10$ \\
\hline Olives & $+5 \ldots+8$ & $85-90$ & $4-6$ weeks & $2-3$ & $0-1$ \\
\hline Strawberry & $0 \ldots+5$ & $90-95$ & 3 weeks & 2 & 2 \\
\hline Onion sliced & 0 & $65-75$ & 8 months & $5-10$ & $3-5$ \\
\hline Bell pepper & $+7,5$ & $95-98$ & 3-5 weeks & 3 & 5 \\
\hline Peach & $-0,5 \ldots 0$ & $90-95$ & 4-6 weeks & $1-2$ & $3-5$ \\
\hline Green tomatoes & $+12 \ldots+13$ & $90-95$ & 6 -10 weeks & $3-5$ & $0-1$ \\
\hline Red tomatoes & +2 & $85-90$ & 30 days & $3-5$ & $2-3$ \\
\hline Rose tomatoes & +8 & $90-95$ & 40 days & $3-5$ & $0-1$ \\
\hline Plum & $-0,5 \ldots 0$ & $90-95$ & $7-8$ weeks & 3 & 5 \\
\hline Merry & $0 \ldots+5$ & $90-95$ & 30 days & $3-10$ & $10-15$ \\
\hline Garlic & $0 \ldots+1$ & $65-75$ & $6-9$ months & 3 & 5 \\
\hline Apple & $0 \ldots+2$ & $90-95$ & до 12 months & $1-3$ & $1-5$ \\
\hline $\begin{array}{l}\text { Berries: } \\
\text { blackberry, } \\
\text { blueberries, } \\
\text { cranberry, } \\
\text { raspberry }\end{array}$ & +5 & 90 & $\begin{array}{c}4-6 \\
\text { weeks }\end{array}$ & $5-10$ & $15-20$ \\
\hline
\end{tabular}

Figure 2. Requirements of the storing of vegetables and fruits by the technology «ULO».

Protégé software can convert the created ontology to the knowledge base of the expert system, which can be created with using the programming language CLIPS (C Language Integrated Production System).

The requirements of the storing for some types of vegetables and fruits are similar that's why the created ontology of the subject area will be using in the expert system for searching some types of vegetables and fruits, which can be storing together. This expert system, which will be created with using the programming language CLIPS, will manage of the automation system of the storehouse for the storing of vegetables and fruits by the technology «ULO». 


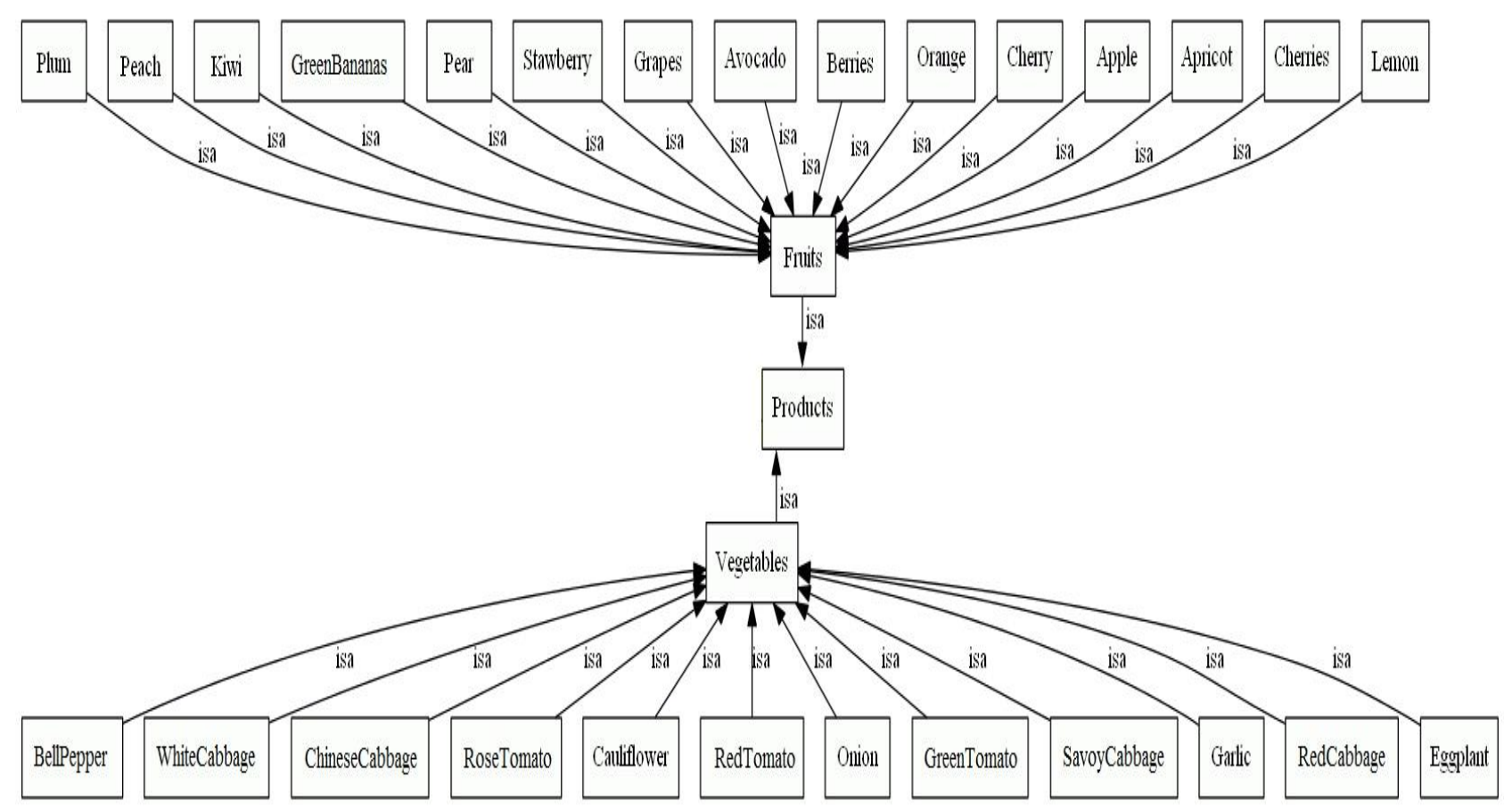

Figure 3. Graph model of the created ontology.

\begin{tabular}{|c|c|}
\hline \multicolumn{2}{|c|}{ Orange } \\
\hline Days & 84 \\
\hline Name & orange \\
\hline $\mathrm{CO} 2$ & 2,5 \\
\hline Temp & $0-9$ \\
\hline Hum & $85-90$ \\
\hline O2 & $5-10$ \\
\hline
\end{tabular}

Figure 4. Example of the filling class Orange in the ontology.

The definition some types of vegetables and fruits, which can be storing together, will allow to optimize the work of the storehouse and increase his productivity.

\section{References}

1. Chambers with adjustable gas environment (AGE). URL: http://www.brandcold.com/?page=57 (in Russian) (date of treatment: 16.05.2019).

2. Storing of vegetables and fruits. URL: http://fermer.org.ua/stati/ovoschevodstvo/hranenie-ovoschei-i-fruktov11096.html (in Russian) (date of treatment: 16.05.2019). 
3. Adjustable gas environment. URL: http://uzholod.uz/texnologiixraneniya/reguliruemaya-gazovaya-sreda-rgs/ (in Russian) (date of treatment: 16.05.2019).

4. Proskurka, Y.S. Building the knowledge base using ontologies for the functioning of the expert system based on precedents / Y.S. Proskurka // Materials of the 79th International Scientific Conference of Young Scientists, Graduates and Students, 2 - 3 April. - K.: NUFT. - 2013. - P. 563-564. (in Ukrainian). 